\title{
Effects of biochar application on nitrogen leaching, ammonia volatilization and nitrogen use efficiency in two distinct soils
}

\author{
Zunqi Liu ${ }^{1,2}$ Tianyi He ${ }^{1,2}$ Ting Cao ${ }^{1,2}$ Tiexing Yang ${ }^{1,2}$ Jun Meng $^{2 *}$, and Wenfu Chen ${ }^{1,2}$
}

${ }^{1}$ Agronomy College, Shenyang Agricultural University, Shenyang, China. ${ }^{2}$ Liaoning Biochar Engineering \& Technology Research Centre, Shenyang, China. *Corresponding author: 13314008862@163.com

\begin{abstract}
This study was conducted to determine the effect of biochar application on nitrogen $(\mathrm{N})$ leaching, ammonia $\left(\mathrm{NH}_{3}\right)$ volatilization, and fertilizer $\mathrm{N}$ use efficiency (NUE) in two soils with different properties (loamy and sandy). Ryegrass (Lolium perenne L.) incubation experiments (with ${ }^{15} \mathrm{~N}$-enriched urea applied) and an $\mathrm{N}$ loss simulation study were conducted at biochar application rates of $2 \%$ and $4 \%$. The results showed that ${ }^{15} \mathrm{~N}$ utilization increased by $8.83-9.06 \%$ following the addition of biochar to sandy soil during the first season compared with the control. However, this significant effect was not observed in the loamy soil, in which significantly more urea- $\mathrm{N}$ was retained in the soil following biochar application. Furthermore, based on the results of the $\mathrm{N}$ leaching and $\mathrm{NH}_{3}$ volatilization experiments, $29.19 \%$ and $28.65 \% \mathrm{NO}_{3}-\mathrm{N}$ leaching reductions were induced by $2 \%$ and $4 \%$ biochar amendments in loamy soil, decreasing the total inorganic $\mathrm{N}$ that was leached $\left(\mathrm{NH}_{4}{ }^{+}-\mathrm{N}\right.$ plus $\left.\mathrm{NO}_{3}-\mathrm{N}\right)$ by $26.46 \%$ and $26.82 \%$, respectively. However, although the amount of leached $\mathrm{NH}_{4}{ }^{+}-\mathrm{N}$ decreased in biochar-amended sandy soil, the cumulative $\mathrm{NH}_{3}$ volatilizations were $14.18-20.05 \%$ higher than in the control, and 22.55\% more $\mathrm{NO}_{3}-\mathrm{N}$ was leached from biochar-amended sandy soil, resulting in a negative effect on $\mathrm{N}$ retention. According to this study, biochar can be effectively used to improve the NUE in sandy soil and reduce $\mathrm{N}$ loss from loamy soil.
\end{abstract}

Keywords: Biochar, nitrogen retention, nitrogen loss, loamy soil, sandy soil 


\section{Introduction}

Nitrogen $(\mathrm{N})$ is an essential element that is required for plant growth, and the application of $\mathrm{N}$ fertilizer to agricultural soil is an effective measure for enhancing crop yields. Farmers, especially in developing countries, often apply $\mathrm{N}$ fertilizer in excessive amounts in an attempt to maximize yields. In 2008, the amount of $\mathrm{N}$ fertilizer applied in China was $2.3 \times 10^{7} \mathrm{t}$, accounting for $1 / 3$ of the total $\mathrm{N}$ consumption worldwide (Zhu. 2008). This excessive $\mathrm{N}$ application results in a decrease in nitrogen use efficiency (NUE) and pollutes the adjacent water and atmospheric systems (Yoo et al., 2014). Those $\mathrm{N}$ losses represent the inherent inefficiencies in current nutrient management systems and result in not only environmental pollution but also additional economic costs to farmers.

The application of biochar to agricultural soil is a potential way of increasing nutrient bioavailability and decreasing nutrient leaching from soil (Shen et al., 2016; Lehmann et al., 2003). Many studies have reported that biochar incorporation could reduce inorganic $\mathrm{N}$ leaching and increase $\mathrm{N}$ retention in the soil (Major et al., 2012; Sun et al., 2017; Yao et al., 2012). The mechanisms underpinning the effects of biochar on $\mathrm{N}$ retention in soil are not well understood, but some potential processes have been proposed: a). Biochar has a high cation exchange capacity (CEC) (Ding et al., 2010; Nelissen et al., 2012) and changes the soil pH (Novak et al., 2009), leading to the direct absorption of $\mathrm{NH}_{4}^{+}$and $\mathrm{NO}_{3}^{-}$. b). Biochar can enhance the water-holding capacity (WHC) of the soil and thus reduce the total volume of leachate (Ouyang et al., 2013; Zheng et al., 2013). c). Due to microbial immobilization (Ippolito et al., 2012), biochar, especially when pyrolyzed at low temperatures, usually contains considerable amounts of labile carbon (Nelissen et al., 2012). This carbon can serve as a microbial substrate, resulting in microbial demand for inorganic $\mathrm{N}$, which thereby immobilizes the $\mathrm{N}$ through biotic processes (Lehmann et al., 2003 Nelissen et al. 2012 and 2014; Zheng et al. 2013). Ammonia volatilization is another mechanism that accounts for the loss of fertilizerderived $\mathrm{N}$. This process tends to increase following the addition of biochar (Reverchon et al., 2014; Yang et al., 2015) because most biochars have a high $\mathrm{pH}$ and serve as liming agents (Novak et al., 2009). However, previous studies have shown that biochar could adsorb ammonia through its functional acid groups (Asada et al., 2002) or through its high CEC (Taghizadehtoosi et al., 2012).

Northeast China is a key location for commercial food production. The sandy soil in this area is dominated by low-activity clays and soil organic matter, with low fertility and WHC. N leaching from sandy soils is considerably higher than that from other agriculture soils (Wang et al., 2015), resulting in a low NUE. Although the loamy soils in this region usually contain high levels of organic matter and high $\mathrm{N}$ fertility, harvesting the biomass removes substantial amounts of nutrients from soils, and the soil fertility and organic matter have declined rapidly in recent years (Gao et al., 2009). To maximize crop production, large amounts of $\mathrm{N}$ fertilizer are input annually, leading to a total $\mathrm{N}$ loading that is much greater than the crop $\mathrm{N}$ demand. Given that the benefits of biochar application vary with soil type and land use and to avoid the negative impact of biochar in field applications, it is important to understand how biochar influences the fate of fertilizer $\mathrm{N}$ (urea) from the two major agricultural soils in Northeast China.

In this study, the authors conducted an isotope $\left({ }^{15} \mathrm{~N}\right)$ tracing study and leaching experiments to determine whether biochar application is an effective measure for controlling $\mathrm{N}$ losses from loamy and sandy soils. The specific objective of this study was to quantify 
the changes in the NUE when biochar was added as a soil amendment and to investigate the potential ability of biochar to reduce inorganic $\mathrm{N}$ leaching and $\mathrm{NH}_{3}$ volatilization.

\section{Material and Methods}

\subsection{Soils and biochars}

Loamy soil was collected from Shenyang Agriculture University $\left(41^{\circ} 83^{\prime} \mathrm{N}, 123^{\circ} 58^{\prime} \mathrm{E}\right)$, and the previous crop was maize. Sandy soil was collected from local farmland near Zhangwu County $\left(42^{\circ} 25^{\prime} \mathrm{E}, 122^{\circ}\right.$ $66^{\prime} \mathrm{N}$ ), Liaoning Province, and the previous crop was peanut. According to the FAO classification system, the loamy and sandy soils used in the present study were classified as a Hapli-Udic Cambisol and an
Arenosol, respectively. Soil samples from the top 20 $\mathrm{cm}$ were collected at the end of each growing season, air dried for 2 weeks and passed through a 2-mm sieve for future study. The basic properties of the soils used here are shown in Table 1.

The commercially available maize stover biochar used in this study was produced under "oxygen-limited" conditions at $400-500{ }^{\circ} \mathrm{C}$ for approximately 2 hours by Jinhefu Agricultural Development Company, Liaoning, China. Thirty-five percent of the maize stover biomass was converted to biochar. The biochar was comminuted by being passed through a $2-\mathrm{mm}$ sieve and then thoroughly mixed to obtain a fine homogeneity that would allow it to be mixed more uniformly with the soil. The basic properties of the biochar are shown in Table 1.

Table 1. Basic properties of the tested soils and biochar

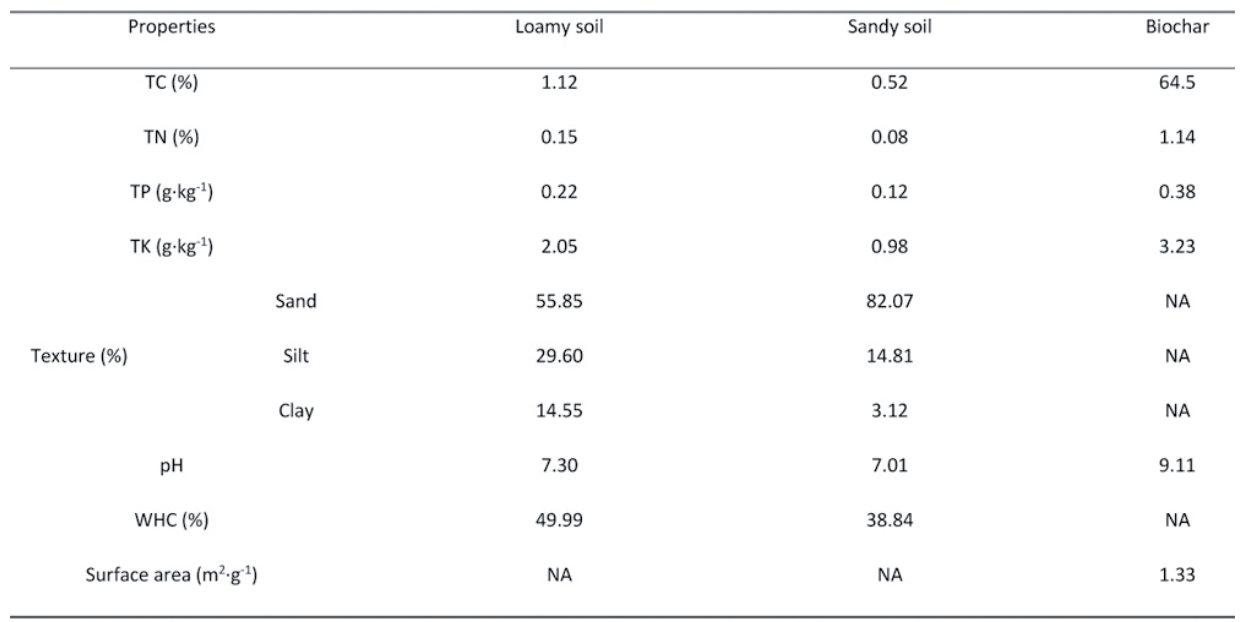

For $\mathrm{pH}$ determination, soil:water $=1: 2.5$; biochar:water $=1: 25$

TC: Total Carbon; TN: Total Nitrogen; TP: Total Phosphorus; TK: Total Potassium; WHC: Water-Holding Capacity; NA: Not Available. 


\subsection{Ryegrass incubation experiment}

A two-season ryegrass (Lolium perenne L.) cultivation experiment was conducted. For each soil, three treatments were performed in triplicate: (1) soil alone (control), (2) soil amended with $2 \%(\mathrm{w} / \mathrm{w})$ biochar $(2 \% \mathrm{BC})$, and (3) soil amended with $4 \%(\mathrm{w} / \mathrm{w})$ biochar $(4 \% \mathrm{BC}) .{ }^{15} \mathrm{~N}$-enriched urea, with an enrichment of 50.16 atom $\%$, was applied as the $\mathrm{N}$ fertilizer at a rate of $280 \mathrm{mg} \cdot \mathrm{kg}^{-1}$ soil.

After the soil samples and biochar were dried and sieved through a $2-\mathrm{mm}$ sieve, 4 or $8 \mathrm{~g}$ of biochar was mixed thoroughly with 200 -g soil samples. Of this $200 \mathrm{~g}, 180 \mathrm{~g}$ was used to fill a 450-mL Mason jar, and then $0.5 \mathrm{~g}$ of ryegrass seeds was sown; the remaining $20 \mathrm{~g}$ of soil was used to fill the jar to the top. A urea solution and deionized water were then added to increase the soil moisture to $60 \%$ WHC.

All jars were placed in a growth cabinet for the first 40 days under an alternating day/night temperature and light regime of $27 / 15^{\circ} \mathrm{C}$ and $14 / 10 \mathrm{~h}$, respectively, with a relative humidity of $60 \%$. Each jar was weighed daily, and the water loss was supplemented. After the 40-day incubation, the ryegrass was sampled, dried at $65{ }^{\circ} \mathrm{C}$ to a constant weight, and $5 \mathrm{~g}$ soil was collected for future study. During season 2, the soil and incubation conditions were the same as those used in season 1 but without the application of urea. After the dry weight of the ryegrass was determined, the plant samples were finely ground, and the total $\mathrm{C}$ and $\mathrm{N}$ contents were measured using an elemental analyzer (Elementar Macro Cube, Langenselbold, Germany). The ${ }^{15} \mathrm{~N}$ abundance was determined using isotope ratio mass spectrometry (Thermo Fisher, Waltham, MA, USA).

\section{3. $\mathrm{NH}_{3}$ volatilization experiment}

An enclosure method was used to capture and measure the $\mathrm{NH}_{3}$ volatilization, as described by Wang et al. (2002). The rates of biochar and urea amendments were consistent with the previous two experiments. In detail, $80 \mathrm{~g}$ of soil with or without biochar amendment was placed in a 450-mL Mason jar. A urea solution $(8 \mathrm{~mL})$ and deionized water were added to bring the moisture content up to $60 \% \mathrm{WHC}$. The experiments were initiated immediately after wetting. The generated $\mathrm{NH}_{3}$ was trapped in $10 \mathrm{~mL}$ of $2 \%$ boric acid, mixed with methyl red and bromocresol green indicators, and then dispensed into a small vessel inside the incubation jars. The boric acid vessels were removed and replaced daily until the color of the mixed indicator did not change, and the trapped $\mathrm{NH}_{3}$ was titrated with $0.01 \mathrm{M} \mathrm{HCl}$.

\subsection{Leaching experiment}

A leaching experiment was conducted by following a modified method as described by Laird et al. (2010). The leaching columns were designed using a $50-\mathrm{mL}$ (27 mm diameter, $140 \mathrm{~mm}$ long) Plastipak medical syringe (with the piston removed). Each column was fixed with filter papers (New Star, Hanzhou, China), and each contained $15 \mathrm{~g}$ of quartz sand. Then, $20 \mathrm{~g}$ of each soil sample with or without biochar amendment was added, and the bulk density was set so it would be close to that of the field conditions. Finally, $20 \mathrm{~g}$ of quartz sand was used to fill the soil columns to the top to avoid soil disturbance during leaching. A urea solution $\left(6 \mathrm{~g} \cdot \mathrm{L}^{-1}\right)$ was applied at a rate of $280 \mathrm{mg} \cdot \mathrm{kg}^{-1}$ soil. The six treatments were the same as those described for the ryegrass incubation experiment, and each treatment was replicated three times.

Deionized water was added to the soil columns following the application of the urea solution to obtain $60 \% \mathrm{WHC}$, and then, the samples were incubated at $27^{\circ} \mathrm{C}$. After 2 days, the first leaching event began; 20 $\mathrm{mL}$ of deionized water was added to the top of the column, the leachate was collected at the bottom of each 
column until it had totally leached out (approximately 7 hours), and then the leachate volume was recorded. The $\mathrm{NH}_{4}{ }^{+} \mathrm{N}$ and $\mathrm{NO}_{3}-\mathrm{N}$ concentrations in the leachate were measured using a continuous flow analyzer (SEAL AA3, Jean, Germany).

\subsection{Statistical analyses}

The data were analyzed by one-way ANOVA using SPSS version 19 (IBM Corporation, New York, USA). Significant differences among the means were assessed with the least significant difference (LSD) test at a 0.05 probability level. The figures shown in this article were generated using GraphPad Prism 5 (GraphPad Software, Inc., La Jolla, USA) and Microsoft Excel 2003.

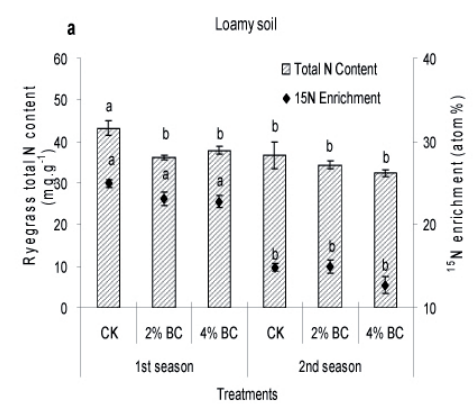

\section{Results}

\subsection{Effect of biochar on nitrogen adsorption and rye- grass growth}

The ryegrass total $\mathrm{N}$ contents and ${ }^{15} \mathrm{~N}$ enrichment were analyzed, and the results are shown in Figure 1. Generally, the biochar application slightly influenced the total $\mathrm{N}$ contents of the ryegrass, and the only significant differences were found in ryegrass grown in loamy soil during the first season, with decreases of 4.0 and $2.29 \mathrm{mg}^{\circ} \mathrm{g}^{-1}$ ryegrass $\mathrm{N}$ following the applications of $2 \%$ and $4 \%$ biochar, respectively, when compared to ryegrass harvested from the control soil.

Figure 1. Effect of biochar addition on the total $\mathrm{N}$ content and ${ }^{15} \mathrm{~N}$ enrichment in ryegrass. a. Loamy soil. b. Sandy soil. 2\% BC: soil amended with 2\% (w/w) biochar; 4\% BC: soil amended with $4 \%$ biochar. Different letters indicate a significant difference $(p<0.05)$.

Seasonal differences in ryegrass ${ }^{15} \mathrm{~N}$ enrichment were found in both soils, but biochar-induced differences were only observed in the sandy soil. Specifically, in loamy soil, the ryegrass ${ }^{15} \mathrm{~N}$ enrichment reached $22.8-24.9$ atom $\%{ }^{15} \mathrm{~N}$ during the first season, which decreased to $12.7-15.0$ atom $\%{ }^{15} \mathrm{~N}$ during the second season, and the values showed significant reductions in the sandy soil. However, significant effects induced by biochar application only occurred in sandy soil, in which the values were significantly lower than the control when $2 \%$ and $4 \%$ biochar was applied during the first season and when $4 \%$ biochar was applied during the second season. The ryegrass dry weights and the proportion of $\mathrm{N}$ derived from fertilizer and soil are presented in Table 2. 
Table 2. The total amount and proportion of ryegrass $\mathrm{N}$ uptake from fertilizer and soil

\begin{tabular}{|c|c|c|c|c|c|c|c|}
\hline & \multirow{2}{*}{ Treatments } & \multirow{2}{*}{ Total ryegrass $\mathrm{N}\left(\mathrm{mg} \cdot \mathrm{pot}^{-1}\right)$} & \multicolumn{2}{|c|}{ Ryegrass $\mathrm{N}$ derived from fertilizer } & \multicolumn{2}{|c|}{ Ryegrass $\mathrm{N}$ derived from soil } & \multirow{2}{*}{ Ryegrass dry weight (g) } \\
\hline & & & Total amount $\left(\mathrm{mg} \cdot \mathrm{pot}^{-1}\right)$ & Ratio (\%) & Total amount $\left(\mathrm{mg} \cdot \mathrm{pot}^{-1}\right)$ & Ratio (\%) & \\
\hline \multirow{7}{*}{$1^{\text {st }}$ season } & \multicolumn{7}{|l|}{ Loamy soil } \\
\hline & CK & $37.75 \pm 0.43 \mathrm{a}$ & $18.62 \pm 0.36 \mathrm{a}$ & $49.32 \mathrm{a}$ & $19.12 \pm 0.44 \mathrm{ab}$ & 50.68 & $0.88 \pm 0.03 \mathrm{ab}$ \\
\hline & $2 \% \mathrm{BC}$ & $32.15 \pm 1.17 \mathrm{~b}$ & $14.7 \pm 1.05 \mathrm{~b}$ & $45.72 \mathrm{ab}$ & $17.4 \pm 0.20 \mathrm{~b}$ & 54.28 & $0.89 \pm 0.04 \mathrm{ab}$ \\
\hline & Sandy soil & $37.09 \pm 2.29 \mathrm{a}$ & $16.75 \pm 1.55 \mathrm{ab}$ & $45.16 \mathrm{ab}$ & $20.34 \pm 0.80 \mathrm{a}$ & 54.84 & $0.98 \pm 0.08 \mathrm{a}$ \\
\hline & CK & $20.59 \pm 1.09 \mathrm{c}$ & $10.23 \pm 0.54 \mathrm{c}$ & $49.68 \mathrm{a}$ & $10.35 \pm 0.85 \mathrm{c}$ & 50.32 & $0.58 \pm 0.02 \mathrm{c}$ \\
\hline & $\begin{array}{l}2 \% \mathrm{BC} \\
4 \% \mathrm{BC}\end{array}$ & $\begin{array}{l}34.10 \pm 0.96 a b \\
35.32 \pm 0.66 a b\end{array}$ & $\begin{array}{l}15.31 \pm 0.35 b \\
15.18 \pm 0.34 b\end{array}$ & $\begin{array}{l}44.90 \mathrm{ab} \\
43.00 \mathrm{~b}\end{array}$ & $\begin{array}{c}18.79 \pm 0.38 \mathrm{ab} \\
20.14 \pm 0.94 \mathrm{a}\end{array}$ & $\begin{array}{l}55.10 \\
57.00\end{array}$ & $\begin{array}{l}0.79 \pm 0.05 b \\
0.83 \pm 0.01 b\end{array}$ \\
\hline & Loamy soil & & & & & & \\
\hline \multirow{7}{*}{$\begin{array}{c}2^{\text {nd }} \\
\text { season }\end{array}$} & CK & $19.44 \pm 2.37 \mathrm{a}$ & $5.63 \pm 0.54 \mathrm{bc}$ & $28.48 \mathrm{c}$ & $13.81 \pm 1.84 \mathrm{a}$ & 71.52 & $0.53 \pm 0.02 \mathrm{ab}$ \\
\hline & $2 \% \mathrm{BC}$ & $17.79 \pm 1.03 \mathrm{a}$ & $5.19 \pm 0.2 \mathrm{bc}$ & $29.17 \mathrm{c}$ & $12.60 \pm 0.93 \mathrm{ab}$ & 70.83 & $0.52 \pm 0.02 \mathrm{ab}$ \\
\hline & $4 \% \mathrm{BC}$ & $17.67 \pm 0.30 \mathrm{a}$ & $4.40 \pm 0.41 \mathrm{c}$ & $24.90 \mathrm{~d}$ & $13.27 \pm 0.17 \mathrm{ab}$ & 75.10 & $0.55 \pm 0.01 \mathrm{a}$ \\
\hline & \multicolumn{7}{|l|}{ Sandy soil } \\
\hline & CK & $19.01 \pm 1.53 \mathrm{a}$ & $7.76 \pm 0.69 \mathrm{a}$ & $40.82 \mathrm{a}$ & $11.25 \pm 0.85 \mathrm{ab}$ & 59.18 & $0.45 \pm 0.02 b$ \\
\hline & $2 \% \mathrm{BC}$ & $16.29 \pm 0.52 \mathrm{a}$ & $6.72 \pm 0.21 \mathrm{ab}$ & $41.25 \mathrm{ab}$ & $10.03 \pm 0.38 \mathrm{~b}$ & 58.75 & $0.45 \pm 0.02 \mathrm{~b}$ \\
\hline & $4 \% \mathrm{BC}$ & $18.67 \pm 1.6 \mathrm{a}$ & $6.70 \pm 0.69 \mathrm{ab}$ & $35.89 \mathrm{~b}$ & $11.97 \pm 0.91 \mathrm{ab}$ & 64.11 & $0.83 \pm 0.01 \mathrm{a}$ \\
\hline
\end{tabular}

2\% BC: soil amended with 2\% (w/w) biochar; 4\% BC: soil amended with 4\% biochar.

Values represent the means \pm standard errors, where $n=3$.

Different letters represent a significant difference during the same season at the $p<0.05$ level.

Biochar significantly $(p<0.05)$ promoted the adsorption of total $\mathrm{N}$, fertilizer $\mathrm{N}$, and soil $\mathrm{N}$ by ryegrass during the first season in the sandy soil. Consequently, compared to the control, the ryegrass dry weight was increased by $36.2 \%$ and $43.1 \%$ following $2 \%$ and $4 \%$ biochar applications, respectively. However, no significant differences were observed during the second season or in loamy soil.

\subsection{Effect of biochar on soil nitrogen contents}

Following two seasons of cultivation, the total $\mathrm{N}$ contents of the loamy soil averaged $0.1 \%$ and $0.14 \%$, and the addition of $4 \%$ biochar significantly increased the soil total $\mathrm{N}$ content by $27.4 \%$ (Figure 2). However, the total $\mathrm{N}$ contents in the sandy soil only averaged
$0.029 \%$ and $0.034 \%$ among the three treatments, and the biochar addition had no significant effect on the total $\mathrm{N}$ content when compared to the control soil. The greatest difference in soil ${ }^{15} \mathrm{~N}$ enrichment was observed in loamy and sandy soils (Figure 2).

In the loamy soil, the ${ }^{15} \mathrm{~N}$ enrichment increased by 0.30 atom $\%{ }^{15} \mathrm{~N}$ and 0.34 atom $\%{ }^{15} \mathrm{~N}$ following the application of $2 \%$ and $4 \%$ biochar, respectively.

No significant differences were observed between the two biochar applications rates used, indicating that the addition of biochar could increase the capacity for fertilizer $\mathrm{N}$ retention in loamy soil. However, in the sandy soil, there were decreases of 0.43 atom $\%$ and 0.54 atom $\%{ }^{15} \mathrm{~N}$ upon the addition of $2 \%$ and $4 \%$ biochar, respectively. 


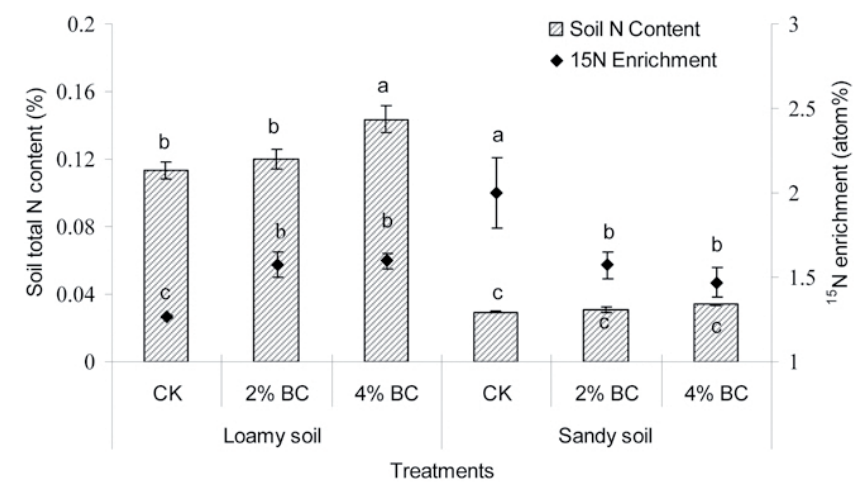

Figure 2. Effect of biochar application on total $\mathrm{N}$ contents and ${ }^{15} \mathrm{~N}$ enrichment in the soil at the end of incubation. 2\% BC: soil amended with 2\% (w/w) biochar; 4\% BC: soil amended with 4\% biochar. Different letters indicate significant differences $(p<0.05)$.

\subsection{Effects of biochar on $\mathrm{NH}_{3}$ volatilization}

The total $\mathrm{NH}_{3}$ volatilization from the soil increased markedly within 5-6 days of the urea application (Figure 3). The cumulative $\mathrm{NH}_{3}$ volatilization from loamy soil ranged from 2.87 to $3.67 \mathrm{mg} \cdot \mathrm{kg}^{-1}$, and it was markedly lower than that of the sandy soil (39.37-47.23

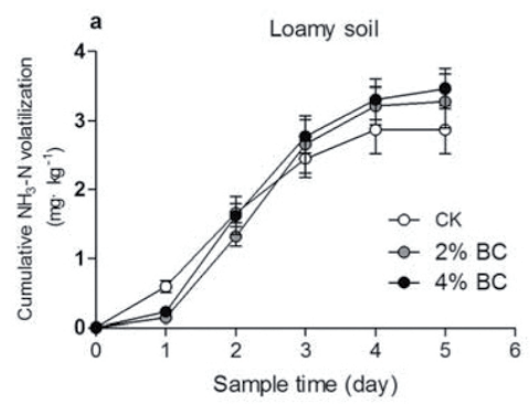

$\left.m g \cdot \mathrm{kg}^{-1}\right)$. The stimulation of $\mathrm{NH}_{3}$ volatilization following biochar addition was observed in both types of soil. Compared with the control treatment, significantly more $(27.87 \%) \mathrm{NH}_{3}$ was volatilized following the addition of $4 \%$ biochar to loamy soil, and $14.18 \%$ and $19.99 \%$ increases were observed after the addition of $2 \%$ and $4 \%$ biochar, respectively, to the sandy soil.

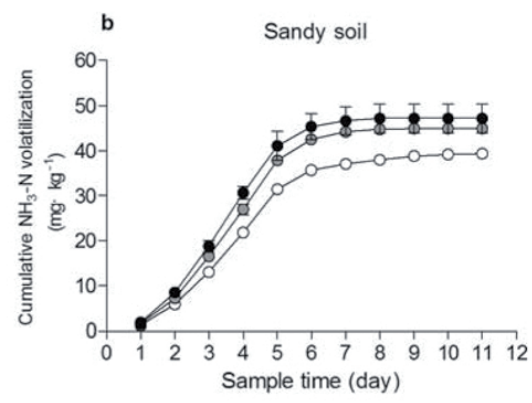

Figure 3. Cumulative ammonia volatilization from soil with and without $2 \%$ and $4 \%$ biochar amendments following urea applications in a. loamy soil and b. sandy soil 


\subsection{Effect of biochar on N leaching from soil}

As shown in Figure 4, there were marked differences in inorganic $\mathrm{N}$ leaching between the loamy and sandy soils. In the loamy soil, most of the $\mathrm{NH}_{4}{ }^{+}-\mathrm{N}$ was leached during the last three leaching events, which occurred during days 20-40 of the incubation, and less than $3 \mathrm{mg} \cdot \mathrm{kg}^{-1} \mathrm{NH}_{4}{ }^{+}-\mathrm{N}$ was leached prior to the 20-day incubation period. By contrast, $90 \%$ of the leached $\mathrm{NH}_{4}{ }^{+}-\mathrm{N}$ from the sandy soil was leached during the first one or two events, with minimal $\mathrm{NH}_{4}{ }^{+}-\mathrm{N}$ leaching observed during later events. This finding indicates that loamy soil was better at retaining $\mathrm{NH}_{4}{ }^{+}-\mathrm{N}$ than sandy soil. The positive effect of biochar on the total $\mathrm{NH}_{4}{ }^{+}-\mathrm{N}$ leaching was only found in sandy soil, wherein the addition of $2 \%$ and $4 \%$ biochars reduced
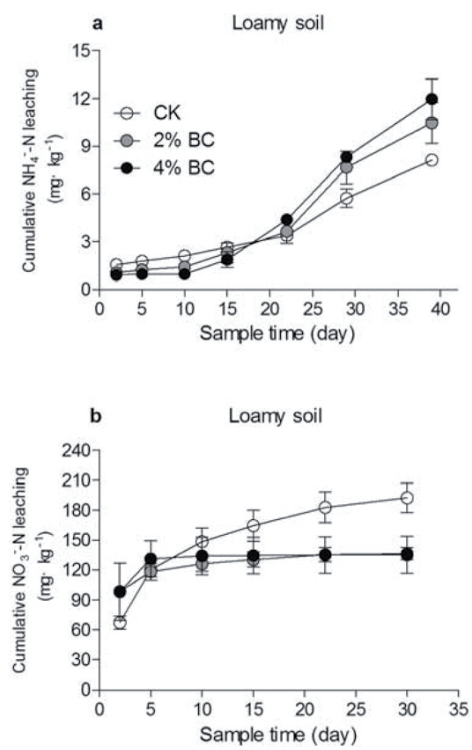

the leached $\mathrm{NH}_{4}{ }^{+}-\mathrm{N}$ to 2.59 and $3.56 \mathrm{mg} \bullet \mathrm{kg}^{-1}$, respectively, which corresponded to $48.5 \%$ and $66.7 \%$ of the total $\mathrm{NH}_{4}{ }^{+}-\mathrm{N}$ leached from the control soil. However, the negative effects of biochar addition on $\mathrm{NH}_{4}{ }^{+}-\mathrm{N}$ leaching were observed in the loamy soil (Figure 4a). The cumulative amount of $\mathrm{NO}_{3}^{-}-\mathrm{N}$ leached from the loamy soil was considerably higher than that leached from sandy soil (Figure 4b, d), and the leaching behavior was different between the two soils. Specifically, compared with the control, significantly $(p<0.05)$ more $(43.6 \%) \mathrm{NO}_{3}-\mathrm{N}$ leached from the sandy soil under the $4 \% \mathrm{BC}$ treatment, but no effect was observed under the $2 \% \mathrm{BC}$ treatment. In the loamy soil, the $\mathrm{NO}_{3}^{-}-\mathrm{N}$ leaching was approximately $30 \%$ lower in the $2 \%$ and $4 \%$ biochar-amended soils, corresponding to a reduction of $57.41 \mathrm{mg} \bullet \mathrm{kg}^{-1} \mathrm{~N}$ compared with the control.
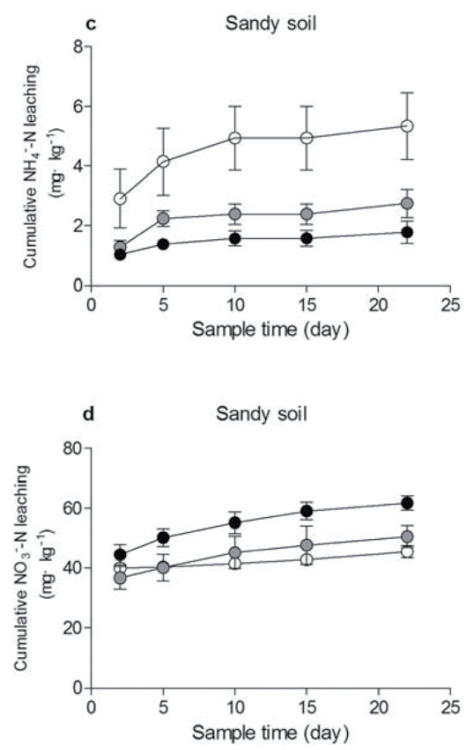

Figure 4. Cumulative nitrogen leaching from loamy soil (a-b) and sandy soil (c-d). $2 \%$ BC: soil amended with $2 \%(\mathrm{w} / \mathrm{w})$ biochar; $4 \% \mathrm{BC}$ : soil amended with $4 \%$ biochar. The data represent the means \pm standard deviations. Different letters indicate significant differences $(p<0.05)$. 


\section{Discussion}

\subsection{Effects of biochar on ryegrass growth and the fate offertilizer $N$}

In the present study, biochar application was observed to have a positive effect on ryegrass growth in sandy soil; however, no significant effect was found in loamy soil. This trend was consistent with a previous meta-analysis, which documented that the soil texture is a factor related to the plant growth response to biochar addition. Specifically, biochar could promote crop growth in soil with coarse textures rather than in fine-textured soil (Jeffery et al., 2011). The increased ryegrass growth could also be attributed to the promoted ryegrass $\mathrm{N}$ adsorption by biochar. Based on our data (Table 2 and Table 3), the total $\mathrm{N}$ uptake and NUE were significantly increased by $14.73{\mathrm{~g} \bullet \mathrm{pot}^{-1}}^{-1}$ and $7.9 \%$ (in the first season), respectively, following the addition of biochar to the sandy soil.
This result was consistent with the finding of Huang et al. (2014), who showed that biochar application resulted in a $23-27 \%$ increase in fertilizer $\mathrm{N}$ uptake by rice. Additionally, our data showed that adding $2 \%$ and $4 \%$ biochar increased fertilizer $\mathrm{N}$ utilization by $9.06 \%$ and $8.83 \%$ and soil $\mathrm{N}$ by $81.55 \%$ and $94.59 \%$, respectively, compared with the corresponding control. The results demonstrated that biochar not only promoted fertilizer $\mathrm{N}$ utilization but also enhanced soil $\mathrm{N}$ availability to the plant. This result occurred because biochar can act as a soil conditioner, altering the soil chemical and microbial properties and resulting in an increased uptake of soil nutrients that were not available in otherwise poor soils (Shen et al., 2016; van Zwieten et al., 2010a). For specific nutrients, soil $\mathrm{N}$ might be mineralized into inorganic $\mathrm{N}$ when $\mathrm{N}$ supplementation is not sufficient for plant use or when the demand for biochar induces microbial activity (Nelissen et al., 2012; Muhammad et al., 2016).

Table 3. Effect of biochar on the rate of recovery and loss of labeled urea

\begin{tabular}{|c|c|c|c|c|c|c|c|}
\hline & \multirow{2}{*}{ Treatments } & \multicolumn{3}{|c|}{ NUE (\%) } & \multirow{2}{*}{${ }^{15} \mathrm{~N}$ residual ratio $(\%)$} & \multirow{2}{*}{ Total recovery $(\%)$} & \multirow{2}{*}{ Loss rate $(\%)$} \\
\hline & & 1st season & 2nd season & Total & & & \\
\hline \multirow{3}{*}{ Loamy soil } & $\mathrm{CK}$ & $32.67 \mathrm{a}$ & $10.05 \mathrm{bc}$ & $42.72 \mathrm{a}$ & $7.31 \mathrm{c}$ & $50.03 \mathrm{a}$ & 49.97 \\
\hline & $2 \% \mathrm{BC}$ & $26.35 \mathrm{~b}$ & $9.27 b c$ & $35.62 \mathrm{~b}$ & $10.35 \mathrm{~b}$ & $45.97 \mathrm{ab}$ & 54.03 \\
\hline & $4 \% \mathrm{BC}$ & $29.91 \mathrm{ab}$ & $7.85 \mathrm{c}$ & $37.76 \mathrm{ab}$ & $12.64 \mathrm{a}$ & $50.40 \mathrm{a}$ & 49.60 \\
\hline \multirow{3}{*}{ Sandy soil } & CK & $18.27 \mathrm{c}$ & $13.85 \mathrm{a}$ & $32.12 \mathrm{c}$ & $3.44 \mathrm{~d}$ & $35.56 \mathrm{~d}$ & 64.44 \\
\hline & $2 \% \mathrm{BC}$ & $27.33 \mathrm{~b}$ & $11.19 \mathrm{ab}$ & $38.52 \mathrm{ab}$ & $2.68 \mathrm{e}$ & $41.2 \mathrm{bc}$ & 58.80 \\
\hline & $4 \% \mathrm{BC}$ & $27.10 \mathrm{~b}$ & $11.97 \mathrm{ab}$ & $39.07 \mathrm{ab}$ & $2.69 \mathrm{e}$ & $41.76 \mathrm{bc}$ & 58.24 \\
\hline
\end{tabular}

Unlike the trend in sandy soil, the fertilizer $\mathrm{N}$ residual ratio increased by $3.04 \%$ and $5.33 \%$ in $2 \%$ and $4 \%$ biochar-amended loamy soil, respectively, while the total ryegrass $\mathrm{N}$ uptake and fertilizer $\mathrm{N}$ adsorption were not significantly affected. These results demonstrated that biochar application has contrasting effects on the fate of fertilizer $\mathrm{N}$ in soils with different properties. Previous studies have shown that using biochar as a soil $\mathrm{N}$ conditioner can potentially increase fertilizer $\mathrm{N}$ retention in soil, and explains this benefit was primarily derived from biochar's direct adsorption effect (van Zwieten 
et al., 2010b) or the indirect microbial immobilization effect, because biochar contain energy substance that can serve as microbial substrates (Ippolito et al., 2012); However, in some cases, $\mathrm{N}$ availability may decrease (Lehmann et al., 2003).

\subsection{Effect of biochar on $\mathrm{NH}_{3}$ volatilization}

As indicated in Table 4, the cumulative volatilized $\mathrm{NH}_{3}$ from sandy soil was $39.4-47.2 \mathrm{mg} \bullet \mathrm{kg}^{-1}$, accounting for $42-47 \%$ of the total $\mathrm{N}$ loss. These losses were greater than those from loamy soil, in which the amount and proportion were only 2.9-3.5 $\mathrm{mg} \cdot \mathrm{kg}^{-1}$ and $1.4-2.3 \%$, respectively. This finding can be explained by the fact that coarse soil usually has good aeration conditions and low WHC that favor $\mathrm{NH}_{3}$ volatilization (Wang et al., 2008).

Moreover, $\mathrm{NH}_{3}-\mathrm{N}$ loss via volatilization from biochar-amended loamy soil and sandy soil was greater than their corresponding controls (Figure 3 and Table 4), and the amount of volatilized $\mathrm{NH}_{3}-\mathrm{N}$ increased by $5.1 \%$ as the biochar application rate increased from
$2 \%$ to $4 \%$ in sandy soil. These findings indicated that biochar addition could promote $\mathrm{NH}_{3}$ volatilization from the applied $\mathrm{N}$. This result was consistent with a previous finding by Schomberg et al. (2012), who reported that the $\mathrm{NH}_{3}$ volatilization was increased by the addition of high-ash alkaline biochar with a 7-day incubation. Yang et al. (2015) also found that biochar potentially promoted $\mathrm{NH}_{3}$ volatilization, and they suggested that the enhancement of the soil $\mathrm{pH}$ by biochar was the reason that $\mathrm{NH}_{3}$ volatilization was favored.

Some reports have stated however, that biochar can adsorb $\mathrm{NH}_{3}$, and one proposed mechanism for $\mathrm{NH}_{3}$ adsorption includes the involvement of functional acid groups from biochar (Asada et al., 2002; Taghizadehtoosi et al., 2012). However, it is notable that in those studies, the biochar in use was acidic, with a $\mathrm{pH}$ of $<7$, whereas most biochars are alkaline, with a high $\mathrm{pH}$ value, including the biochar used in the present study. Therefore, we assume that biochars with $\mathrm{pH}$ values $>7$ were not suitable for reducing $\mathrm{NH}_{3}$ volatilization.

Table 4. Total $\mathrm{N}$ loss and the percentage lost through each mechanism

\begin{tabular}{|c|c|c|c|c|c|c|c|c|}
\hline & & \multirow[b]{2}{*}{$\begin{array}{l}\text { Total amount lost } \\
\qquad\left(\mathrm{mg} \cdot \mathrm{kg}^{-1}\right)\end{array}$} & \multicolumn{2}{|c|}{$\mathrm{NH}_{3}$} & \multicolumn{2}{|c|}{$\mathrm{NH}_{4}{ }^{+}-\mathrm{N}$} & \multicolumn{2}{|c|}{$\mathrm{NO}_{3}=\mathrm{N}$} \\
\hline \multicolumn{2}{|c|}{ Treatments } & & $\begin{array}{l}\text { Cumulative } \\
\text { volatilization } \\
\left(\mathrm{mg} \cdot \mathrm{kg}^{-1}\right)\end{array}$ & $\begin{array}{l}\text { Percentage of } \\
\text { total N loss (\%) }\end{array}$ & $\begin{array}{c}\text { Cumulative } \\
\text { leached amount } \\
\quad\left(\mathrm{mg} \cdot \mathrm{kg}^{-1}\right)\end{array}$ & $\begin{array}{c}\text { Percentage of } \\
\text { total N loss (\%) }\end{array}$ & $\begin{array}{c}\text { Cumulative } \\
\text { leached amount } \\
\left(\mathrm{mg} \cdot \mathrm{kg}^{-1}\right)\end{array}$ & $\begin{array}{c}\text { Percentage of total } \mathrm{N} \\
\text { loss }(\%)\end{array}$ \\
\hline \multirow{3}{*}{$\begin{array}{l}\text { Loamy } \\
\text { soil }\end{array}$} & CK & $203.83 \pm 8.38 \mathrm{a}$ & $2.87 \pm 0.2 \mathrm{~b}$ & 1.41 & $8.46 \pm 0.48 b$ & 4.15 & $192.5 \pm 8.42 \mathrm{a}$ & 94.44 \\
\hline & $\begin{array}{l}2 \% \\
\mathrm{BC}\end{array}$ & $151.05 \pm 3.86 b$ & $3.28 \pm 0.22 \mathrm{a}$ & 2.17 & $11.47 \pm 0.29 a b$ & 7.59 & $136.3 \pm 3.57 b$ & 90.24 \\
\hline & $\begin{array}{l}4 \% \\
B C\end{array}$ & $150.52 \pm 10.74 b$ & $3.47 \pm 0.17 \mathrm{a}$ & 2.30 & $11.97 \pm 0.74 \mathrm{a}$ & 7.95 & $135.09 \pm 10.47 \mathrm{~b}$ & 89.75 \\
\hline \multirow{3}{*}{$\begin{array}{l}\text { Sandy } \\
\text { soil }\end{array}$} & CK & $94.8 \pm 2.62 \mathrm{~b}$ & $39.36 \pm 0.21 \mathrm{c}$ & 41.52 & $5.34 \pm 0.65 \mathrm{a}$ & 5.64 & $50.10 \pm 2.97 b$ & 52.84 \\
\hline & $\begin{array}{l}2 \% \\
\mathrm{BC}\end{array}$ & $96.22 \pm 4.0 \mathrm{~b}$ & $44.94 \pm 0.43 b$ & 46.71 & $2.75 \pm 0.27 b$ & 2.86 & $48.53 \pm 4.10 b$ & 50.44 \\
\hline & $\begin{array}{l}4 \% \\
B C\end{array}$ & $110.45 \pm 2.53 \mathrm{a}$ & $47.23 \pm 1.85 \mathrm{a}$ & 42.76 & $1.78 \pm 0.22 \mathrm{c}$ & 1.61 & $61.44 \pm 1.11 \mathrm{a}$ & 55.63 \\
\hline
\end{tabular}

Values represent the means \pm standard errors, where $\mathrm{n}=3$. Different letters represent a significant difference at $p<0.05$ within the same soil treatment. 


\subsection{Effect of biochar on $N$ leaching}

Consistent with a previous report that $\mathrm{NO}_{3}-\mathrm{N}$ is more mobile than $\mathrm{NH}_{4}{ }^{+}-\mathrm{N}$ and could not be easily adsorbed by soil colloids (Wang. 2008), our results showed that $\mathrm{NO}_{3}-\mathrm{N}$ accounted for more than $90 \%$ of the total leached inorganic $\mathrm{N}$ and $50.4-55.6 \%$ and $89.8-94.4 \%$ of the total $\mathrm{N}$ lost from sandy and loamy soil, respectively (Table 4).

Specifically, there were $48.5 \%$ and $66.7 \%$ reductions in the $\mathrm{NH}_{4}{ }^{+}-\mathrm{N}$ following the application of $2 \%$ and $4 \%$ biochar to the sandy soil, respectively. Ding et al. (2010) illustrated that biochar could adsorb $\mathrm{NH}_{4}{ }^{+}-$ $\mathrm{N}$ predominantly through its high $\mathrm{CEC}$, resulting in a $15.2 \%$ reduction in cumulative $\mathrm{NH}_{4}{ }^{+}-\mathrm{N}$ losses. The significant effect may also be due to the enhanced nitrification rate induced by biochar, rendering it less available for leaching. Promising mechanisms have involved biochar that could absorb the potential inhibitors of microbial metabolic pathways, such as monoterpenes and various polyphenolic compounds that are inhibitory to nitrification (Nelissen et al., 2012). However, in loamy soil, $40.3 \%$ more $\mathrm{NH}_{4}{ }^{+}-\mathrm{N}$ was leached from $4 \%$ biochar-amended soil. This significant $(p<0.05)$ effect was attributed to the enhanced mineralization of organic $\mathrm{N}$ that was simulated by a high rate of biochar addition (Laird et al., 2010), thus increasing the soil $\mathrm{NH}_{4}{ }^{+}-\mathrm{N}$ content in the short term. This interpretation is consistent with the accelerated $\mathrm{N}$ dynamic following biochar addition (Nelissen et al., 2014).

For the biochar effect on $\mathrm{NO}_{3}-\mathrm{N}$ leaching, our data showed that $22.6 \%$ more $\mathrm{NO}_{3}^{-}-\mathrm{N}$ was leached from the soil column following the addition of $4 \%$ biochar to sandy soil when compared to the control soil (Table 4). This result occurred because most of the surface charge sites on biochar are due to carboxylate and phenolate groups, and those anionic surface charge sites will not retain $\mathrm{NO}_{3}-$; thus, $\mathrm{NO}_{3}-\mathrm{N}$ was difficult to retain by biochar (Jin et al., 2016). Another possible reason may lie in the finding we noted above in which biochar accelerated the nitrification rate in sandy soil, resulting in more $\mathrm{NO}_{3}^{-}-\mathrm{N}$ being available for leaching. However, this hypothesis cannot be fully supported without additional direct evidence. Although laboratory sorption studies have shown that biochar had a weak ability to adsorb $\mathrm{NO}_{3}-\mathrm{N}$, biochar was reportedly able to mitigate $\mathrm{NO}_{3}{ }^{-}-\mathrm{N}$ leaching as a soil amendment when it was incorporated into the soil (Jin et al., 2016; Laird et al., 2010). For example, Yao et al. (2012) reported that only 4 out of 13 biochars could adsorb $\mathrm{NO}_{3}-\mathrm{N}$, and the 2 biochars added to a sandy soil were shown to reduce the $\mathrm{NO}^{--} \mathrm{N}$ by $34-34.3 \%$. These results contrast with our findings in sandy soil. One possible reason for the inconsistent results may be because the effects of biochar on the $\mathrm{NO}^{-}-\mathrm{N}$ adsorption ability not originated from the CEC but associated with other characteristics, such as its pore size and distribution, surface area and functional groups (Yang et al., 2017), parameters known to vary with biochar types (Jin et al., 2016). The inconsistent result noted above indicated that the effect of biochar on the leaching of agricultural nutrients in soils was not uniform, and it varies by soil and nutrient type (Clough et al., 2013; Yao et al., 2012) as well as the interactions between soil and biochar. The authors speculate that the ability of biochar to engage in $\mathrm{NH}_{4}{ }^{+} \mathrm{N}^{-}$and $\mathrm{NO}_{3}{ }^{-}-\mathrm{N}$ sorption/desorption and its mineralization/immobilization effect on soil $\mathrm{N}$ are two primary factors that control $\mathrm{N}$ leaching. These processes may be affected by abiotic and microbial processes (Bai et al. 2012; Lehmann et al., 2011), clarifying why the results obtained for biochar with respect to $\mathrm{NH}_{4}{ }^{+}-\mathrm{N}$ and $\mathrm{NO}_{3}{ }^{-}-\mathrm{N}$ leaching varied with the soils. Therefore, the nutrient sorption characteristics of a given biochar and the soil reaction to a special biochar should be studied prior to its use in a particular soil amendment project. In summary, biochar showed a significant positive effect in mitigating inorganic $\mathrm{N}$ losses from loamy soil 
(26.46\% and $26.82 \%$ of the reductions occurred after the addition of $2 \%$ and $4 \%$ biochars) and had a neutral effect in sandy soil. The primary benefit in loamy soil came from a significant reduction in the level of $\mathrm{NO}_{3}$ $-\mathrm{N}$ leaching, but the potential mechanisms were not fully investigated and require future study.

\section{Conclusions}

The application of biochar to loamy and sandy soils had different effects on $\mathrm{N}$ utilization and loss. In particular, the results from the ${ }^{15} \mathrm{~N}$ tracing study illustrated that biochar promoted the NUE and soil $\mathrm{N}$ utilization by ryegrass in sandy soil, but significant effects were not observed in loamy soil, where the fertilizer $\mathrm{N}$ retention ratio (\%) was increased by $3.04-5.33 \%$. This finding indicated that biochar is a soil conditioner that can either enhance fertilizer $\mathrm{N}$ availability or increase fertilizer $\mathrm{N}$ retention depending on the soil characteristics. In addition, biochar can markedly reduce $\mathrm{NO}_{3}$ $-\mathrm{N}$ leaching losses from loamy soil, resulting in a $26 \%$ reduction in leached inorganic N. However, N losses via $\mathrm{NH}_{3}$ volatilization were enhanced in the two tested soils, especially in the sandy soil. This finding was primarily a result of the fact that the added biochar was highly alkaline. In conclusion, this study reveals that biochar could improve the NUE in sandy soil and increase N retention while reducing $\mathrm{N}$ loss from loamy soil.

\section{Acknowledgements}

This work was supported by the National Science Fund (No. 41401325), the Chinese Academy of Engineering Consulting Project (No. 2015-XY-25), and the Science and Technology Program of Liaoning Province (No. 2014215019). The authors would like to thank the two anonymous reviewers for their constructive comments, which helped to improve the quality of the manuscript.

\section{References}

Asada, T., Ishihara, S., Yamane, T., Toba, A., Yamada, A., Oikawa, K. 2002. Science of bamboo charcoal: study on carbonizing temperature of bamboo charcoal and removal capability of harmful gases. J. Health Sci. 48, 473-479.

Bai, S.H., Reverchon, F., Xu, C., Xu, Z., Blumfield, T.J., Zhao, H., Van Zwietene, L., Wallace, H.M. 2015. Wood biochar increases nitrogen retention in field settings mainly through abiotic processes. Soil Biol. Biochem. 90, 232-240.

Clough, T.J., Condron, L.M., Kammann, C., Müller, C. 2013. A review of biochar and soil nitrogen dynamics. Agronomy. 3, 275-293.

Ding, Y., Liu, Y., Wu, W., Shi, D., Yang, M. 2010. Evaluation of biochar effects on nitrogen retention and leaching in multi-layered soil columns. Water Air Soil Poll. 213, 47-55.

Gao, X., Han, X., Liu, N., Zuo, R., Wu, Z., Yang, J. 2009. Effects of Long-Term Fertilization on Organic Nitrogen Forms and Their Distribution in Profile of a Brown Soil. Scientia Agr. Sinica. 42, 2820-2827.

Huang, M., Liu, Y., Qin, H., Jiang, L., Zou, Y. 2014. Fertilizer nitrogen uptake by rice increased by biochar application. Biol. Fert. Soils. 50, 9971000

Ippolito, J.A., Novak, J.M., Busscher, W.J., Ahmedna, M., Rehrah, D., Watts, D.W. 2012. Switchgrass biochar affects two aridisols. J. Environ. Qual. 41, 1123-30.

Jeffery, S., Verheijen, F.G.A., Velde, M.V.D., Bastos, A.C., 2011. A quantitative review of the effects of biochar application to soils on crop productivity using meta-analysis. Agr. Ecosyst. Environ. 144, 175-187. 
Jin, Z., Chen, X., Chen, C., Tao, P., Han, Z., Zhang, X. 2016. Biochar impact on nitrate leaching in upland red soil, China. Environ. Earth Sci. 75(14), 1109.

Laird, D., Fleming, P., Wang, B., Horton, R., Karlen, D. 2010. Biochar impact on nutrient leaching from a midwestern agricultural soil. Geoderma. 158, 436-442.

Lehmann, J., Glaser, B. 2003. Nutrient availability and leaching in an archaeological Anthrosol and a Ferralsol of the Central Amazon basin: fertilizer, manure and charcoal amendments. Plant Soil. 249, 343-357.

Lehmann, J., Rillig, M.C., Thies, J., Masiello, C.A., Hockaday, W.C., Crowley, D. 2011. Biochar effects on soil biota - a review. Soil Biol. Biochem. 43, 1812-1836.

Major, J., Rondon, M., Molina, D., Riha, S.J., Lehmann, J. 2012. Nutrient leaching in a colombian savanna oxisol amended with biochar. J. Environ. Qual. 41, 1076-1086.

Muhammad, N., Brookes, P. C., Wu, J. 2016. Addition impact of biochar from different feed stocks on microbial community and available concentrations of elements in a Psammaquent and a Plinthudult. J. Soil Sci. Plant Nutr. 16(1), 137-153. DOI.org/10.4067/S0718-95162016005000010

Nelissen, V., Rütting T., Huygens, D., Ruysschaert, G., Boeckx, P. 2014. Temporal evolution of biochar's impact on soil nitrogen processes-a ${ }^{15} \mathrm{~N}$ tracing study. GCB Bioenergy. 7, 635-645.

Nelissen, V., Rütting, T., Huygens, D., Staelens, J., Ruysschaert, G., Boeckx, P. 2012. Maize biochars accelerate short-term soil nitrogen dynamics in a loamy sand soil. Soil Biol. Biochem. 55, 20-27.

Novak, J.M., Busscher, W.J., Laird, D.L., Ahmedna, M., Watts, D.W., Niandou, M.A.S. 2009. Impact of biochar amendment on fertility of a southeastern coastal plain soil. Soil Sci. 174, 105-112.
Ouyang, L., Wang, F., Tang, J., Yu, L., Zhang, R. 2013. Effects of biochar amendment on soil aggregates and hydraulic properties. J. Soil Sci. Plant Nutr. 13(4), 991-1002.

Reverchon, F., Flicker. R.C., Yang, H., Yan, G., Xu, Z., Chen, C., Bai, S., Zhang, D. 2014. Changes in $\delta^{15} \mathrm{~N}$ in a soil-plant system under different biochar feedstocks and application rates. Biol. Fert. Soils. 50, 275-283.

Schomberg, H.H., Gaskin, J.W., Harris, K., Das, K.C., Novak, J.M., Busscher, W.J., et al. 2012. Influence of biochar on nitrogen fractions in a coastal plain soil. J Environ. Qual. 41, 1087-1095.

Shen, Q., Hedley, M., Camps Arbestain, M., Kirschbaum, M.U.F. 2016. Can biochar increase the bioavailability of phosphorus?. J. Soil Sci. Plant Nutr. 16, 268-286.

Sun, H., Lu, H., Lei, C., Shao, H., Shi, W. 2017. Biochar applied with appropriate rates can reduce $\mathrm{n}$ leaching, keep $\mathrm{N}$ retention and not increase $\mathrm{NH}_{3}$ volatilization in a coastal saline soil. Sci. Total Environ. 575, 820-825.

Taghizadehtoosi, A., Clough, T.J., Sherlock, R.R., Condron, L.M. 2012. Biochar adsorbed ammonia is bioavailable. Plant Soil. 350, 57-69.

Van Zwieten, L., Kimber, S., Downie, A., Morris, S., Petty, S., Rust, J., Chan, K.Y. 2010a. A glasshouse study on the interaction of low mineral ash biochar with nitrogen in a sandy soil. Aus. J. Soil Res. 48(6), 569-576.

Van Zwieten, L., Kimber, S., Morris, S., Downie, A., Berger, E., Rust, J., Scheer, C. 2010b. Influence of biochars on flux of $\mathrm{N}_{2} \mathrm{O}$ and $\mathrm{CO}_{2}$ from ferrosol. Austr. J. Soil Res. 48, 555-568.

Wang, Z., Li, Y., Wang, S., Ju, X., Guan, H., Wang, Y. 2015. Preliminary Study on Nitrogen Leaching Characteristics in Aeolian Sandy Soil and Control Technology. Journal of Soil and Water Conservation. 29, 239-242. 
Wang, Z., Liu, X., Zhang, F., 2002. Field insitu determination of ammonia volatilization from soil: Venting method. Plant Nutrition and Fertilizer Science. 8, 205-209.

Wang. Z. 2008. Soil inorganic nitrogen leaching and residual in dry land, in: Li. S. (eds.), Soil and plant nitrogen in dry land areas of China. Science Press group, Beijing, pp.263-289. (in Chinese)

Yang, F., Cao, X., Gao, B., Zhao, L., Li, F. 2015. Short-term effects of rice straw biochar on sorption, emission, and transformation of soil $\mathrm{NH}_{4+-}$ N. Environ. Sci. Pollut. R. 22, 9184-9192.

Yang, J., Li, H., Zhang, D., Wu, M., Pan, B. 2017. Limited role of biochars in nitrogen fixation through nitrate adsorption. Sci. Total Environ. 592, 758-765.
Yao, Y., Gao, B., Zhang, M., Inyang, M., Zimmerman, A.R. 2012. Effect of biochar amendment on sorption and leaching of nitrate, ammonium, and phosphate in a sandy soil. Chemosphere. 89, 1467-1471.

Yoo, G., Kim, H., Chen, J., Kim, Y. 2014. Effects of Biochar Addition on Nitrogen Leaching and Soil Structure following Fertilizer Application to Rice Paddy Soil. Soil Sci. Soc. of Am. J. 78(3), 852.

Zheng, H., Wang, Z., Deng, X., Herbert, S., Xing, B. 2013. Impacts of adding biochar on nitrogen retention and bioavailability in agricultural soil. Geoderma. 206, 32-39.

Zhu, Z. 2008. Research on soil nitrogen in China. Acta Pedol. Sin. 45, 778-783. 